\title{
NHC-catalyzed thioesterification of aldehydes by external redox activation.
}

\section{$\operatorname{AUTHOR}(\mathrm{S})$ :}

Uno, Takuya; Inokuma, Tsubasa; Takemoto, Yoshiji

\section{CITATION:}

Uno, Takuya ...[et al]. NHC-catalyzed thioesterification of aldehydes by external redox activation.. Chemical communications 2012, 48(13): 1901-1903

ISSUE DATE:

2012-02-11

URL:

http://hdl.handle.net/2433/166620

\section{RIGHT:}

(C) The Royal Society of Chemistry 2012; This is not the published version. Please cite only the published version.; この論文は出版社版で ありません。引用の際には出版社版をご確認ご利用ください。 


\title{
NHC-catalyzed Thioesterification of Aldehydes by External Redox Activation
}

\author{
Takuya Uno, Tsubasa Inokuma and Yoshiji Takemoto* \\ Received (in XXX, XXX) Xth XXXXXXXXX 20XX, Accepted Xth XXXXXXXXX 20XX \\ DOI: 10.1039/b000000x
}

The NHC-catalyzed thioesterification of aromatic or aliphatic aldehydes with a range of thiols was developed in the presence of a stoichiometric amount of an organic oxidant. Among the oxidants examined, phenazine was shown to give ${ }_{10}$ the best results in terms of chemical yield and compatibility with thiols.

Thioesters are important compounds from both synthetic and biological perspectives. They have frequently been used as synthetic intermediates for acyl transfer reactions, ${ }^{1}$ including 15 native chemical ligation, ${ }^{2}$ functional group transformations ${ }^{3}$ into ketone and aldehyde, and the formation of carbon-carbon bonds ${ }^{4}$ such as in the aldol and Michael reactions. In nature, acetyl-CoA, a biologically important thioester, plays a pivotal role in fatty acid and polyketide biosynthesis. ${ }^{5}$ To synthesize such versatile 20 thioesters, various methods have been developed: (1) condensation $^{6}$ of carboxylic acid and thiol with dehydrating reagents, (2) transthioesterification ${ }^{7}$ of active carboxylic acid derivatives with thiol, (3) palladium-catalyzed thiocarbonylation ${ }^{8}$ of iodoarenes and thiol with carbon monoxide, and (4) radical25 mediated coupling ${ }^{9}$ of aldehyde with disulfide or thiol. However, the discovery of efficient catalytic methods for thioesters remains an important synthetic challenge in organic chemistry.

(i) Internal redox reaction<smiles>[Y]/C=C(\O)C1=NCCN1</smiles>

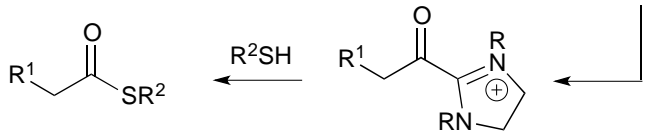

(ii) external redox reaction

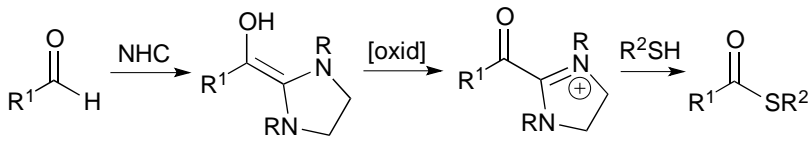

${ }_{30}$ Scheme 1 NHC-Catalyzed thioesterification of aldehydes by the internal and external redox activations.

On the other hand, N-heterocyclic carbene $(\mathrm{NHC})^{10}$-catalyzed redox reactions have been applied to the concise synthesis of 35 esters $^{11,12}$ and amides ${ }^{13,14}$ from aldehydes through the use of internal or external redox protocols. In contrast, there have been fewer studies on NHC-catalyzed thioesterification. In fact, there have been only two previous reports to date, in which either cyclopropyl aldehyde ${ }^{11 \mathrm{c}}$ was used as a substrate or azobenzene ${ }^{15}$ 40 was used as an oxidant for the internal or external redox reaction (Scheme 1). However, each reaction has its own limitations in terms of substrate scope or the formation of side-products. In particular, the choice of an appropriate external oxidant is the key to success in external redox thioesterification. In this paper, we 45 describe a new efficient and practical method for the one-step conversion of aldehyde into the corresponding thioesters using phenazine as an external oxidant.

Table 1 Screening of Oxidants ${ }^{a}$

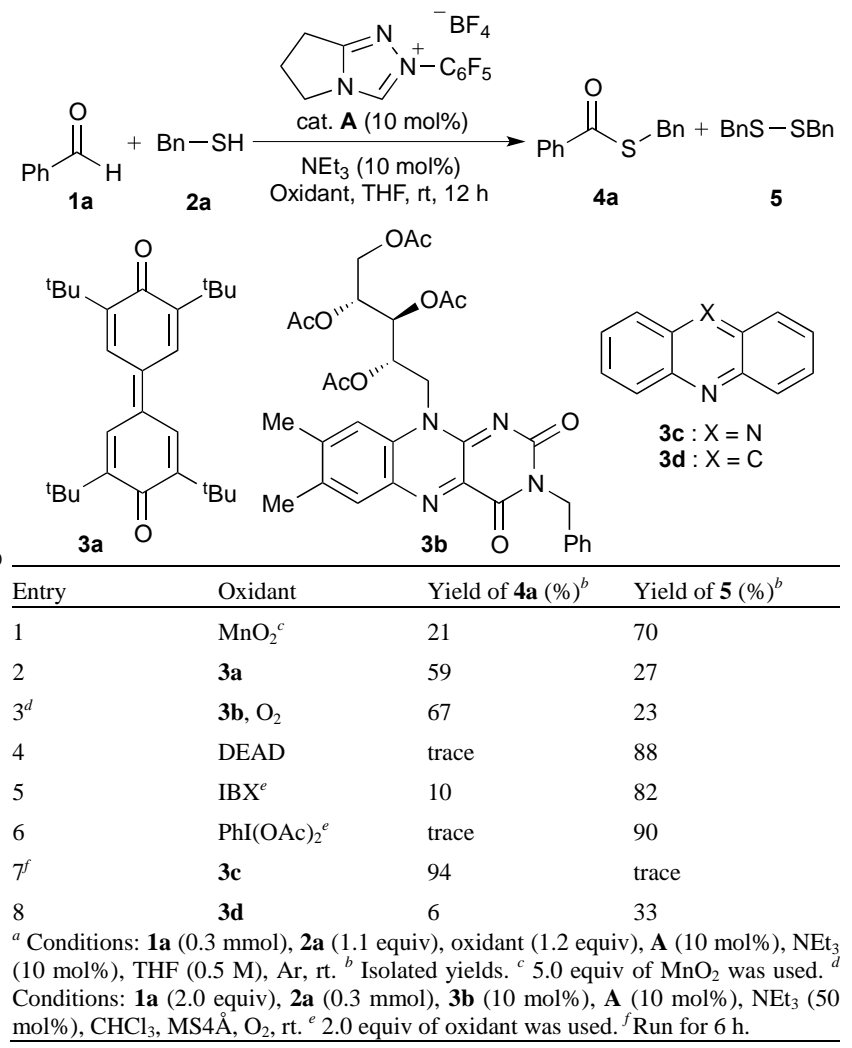

As a model reaction for thioesterification, we examined the reaction of benzaldehyde $\mathbf{1 a}$ and phenylmethanethiol 2a with catalyst $\mathbf{A}(10 \mathrm{~mol} \%)$ and triethyamine $(10 \mathrm{~mol} \%)$ in the presence 
Table 2 Thioesterification of Aromatic Aldehydes ${ }^{a}$

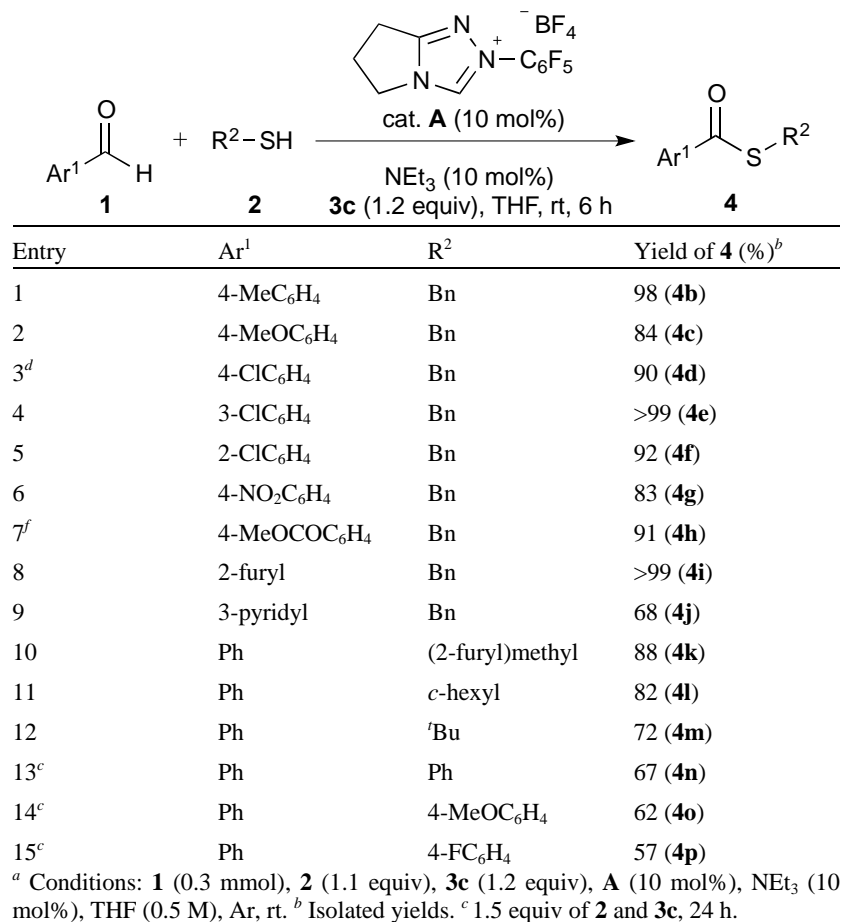

of several oxidants (Table 1). The use of oxidants such as ${ }_{5} \mathrm{MnO}_{2},{ }^{12 \mathrm{~d}, \mathrm{e}}$ quinone $\mathbf{3 a}{ }^{12 \mathrm{c}, 16}$ and riboflavin $\mathbf{3 b},{ }^{17}$ which were used for NHC-catalyzed esterification, gave thioester $\mathbf{4 a}$ in low to moderate yields due to the formation of disulfide 5 (entries 1-3). Other oxidants such as diethyl azodicarboxylate (DEAD), oiodoxybenzoic acid $(\mathrm{IBX})^{18}$ and $\mathrm{PhI}(\mathrm{OAc})_{2}$ gave disulfide $\mathbf{5}$ as 10 the major product along with a trace amount of $\mathbf{4 a}$ (entries 4-6). We then examined heterocyclic compounds $\mathbf{3 c}$ and $\mathbf{3 d}$ as hydrogen acceptors (entries 7 and 8). To our delight, phenazine 3c was shown to be a sufficiently mild oxidant to afford the desired product $\mathbf{4 a}$ in high yield without the formation of any 15 disulfide.

Table 3 Screening of Reaction Conditions for Thioesterification of Aliphaitc Aldehyde

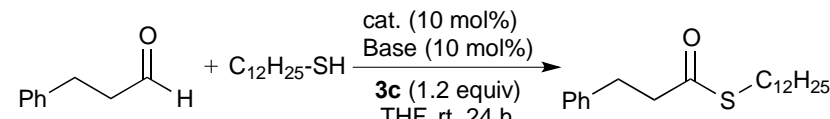

$6 a$ 2b THF, rt, $24 \mathrm{~h}$ $7 \mathrm{a}$

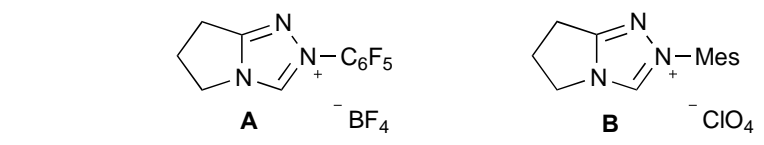

\begin{tabular}{lllll}
\hline Entry & Catalyst & Base & Time (h) & Yield of 7a $(\%)^{b}$ \\
\hline 1 & $\mathbf{A}$ & $\mathrm{Et}_{3} \mathrm{~N}$ & 24 & 55 \\
2 & $\mathbf{A}$ & $\mathrm{DBU}$ & 24 & 71 \\
3 & $\mathbf{B}$ & $\mathrm{Et}_{3} \mathrm{~N}$ & 24 & trace \\
4 & $\mathbf{B}$ & $\mathrm{DBU}$ & 12 & 74 \\
$5^{c}$ & $\mathbf{B}$ & $\mathrm{DBU}$ & 12 & 86 \\
${ }^{c}$ Conditions: $\mathbf{6 a}(0.3 \mathrm{mmol}), \mathbf{2 b}(1.1$ equiv), 3c $(1.2$ equiv), catalyst $\mathbf{A}$ or $\mathbf{B}(10$ \\
mol\%), Base (10 mol\%), THF (0.5 M), rt. ${ }^{b}$ Isolated yields. ${ }^{c}$ 1.5 equiv. of $\mathbf{2 b}$ and 3c \\
were used.
\end{tabular}

After establishing the optimized reaction conditions, we investigated the generality of this thioesterification (Table 2). A wide range of aryl and heteroaryl aldehydes bearing electrondonating and electron-withdrawing groups could be used 25 regardless of their substituted position, to give the corresponding thioesters 4b-j in good to high yields (entries 1-9). With regard to the thiol used, both alkyl and aryl thiols were tolerated under these conditions, while products $\mathbf{4 n - p}$ were obtained in slightly lower yields even with 1.5 equiv of both thiols and $\mathbf{3 c}$ in the case 30 of aryl thiols (entries 10-15).

Table 4 Thioesterification of Aliphatic Aldehydes ${ }^{a}$

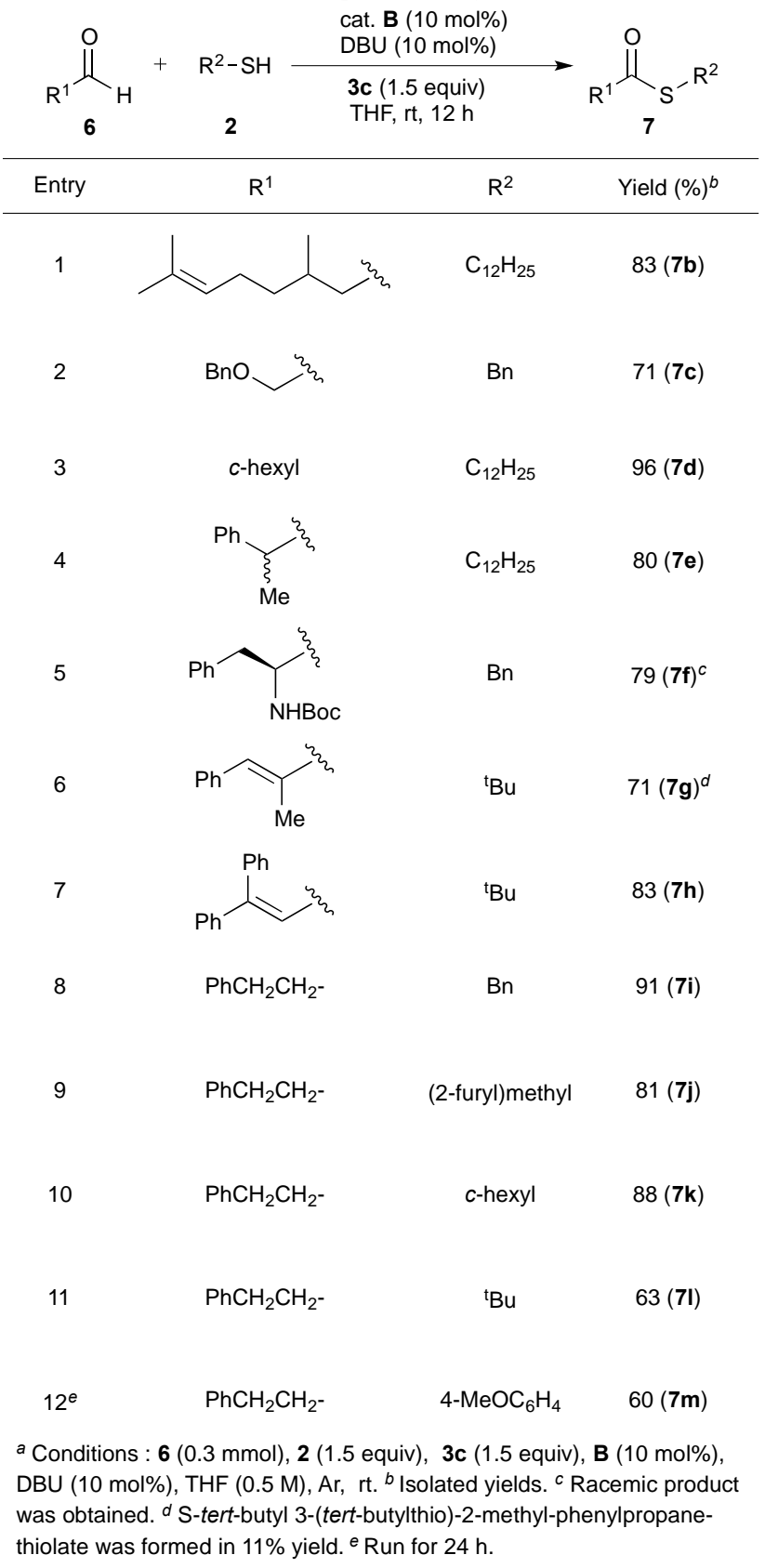

35 We next explored the thioesterification of aliphatic aldehydes (Table 3). When the reaction of 3-phenylpropionaldehyde $\mathbf{6 a}$ with an odorless dodecanethiol $\mathbf{2 b}$ was carried out under the same reaction conditions, the yield of $\mathbf{7 a}$ significantly decreased (entry 
1). This could probably be attributed to the sluggish reaction due to the low reactivity of the aliphatic aldehyde. The use of DBU instead of $\mathrm{Et}_{3} \mathrm{~N}$ improved the chemical yield from 55 to $71 \%$ (entry 2). Replacement of the NHC precatalyst $\mathbf{A}$ by more 5 nucleophilic $N$-mesityl triazolium salt $\mathbf{B}$, along with an increase in the amounts of the thiol and base, led to a further increase in yield, and gave the thioester 7a in $86 \%$ yield (entries $3-5$ ).

We finally applied the optimal reaction conditions to a variety of aliphatic aldehydes (Table 4). Primary and secondary alkyl 10 aldehydes bearing functional groups such as an isolated olefin, ether, and carbamate were converted into the corresponding thioesters $\mathbf{7 b - f}$ in good yields without any problems (entries 1-5). The reaction of chiral $\alpha$-amino aldehyde derivative $6 \mathbf{f}$ was accompanied by racemization to provide the racemic thioester $\mathbf{7 f}$ 15 in $79 \%$ yield. Although $\alpha, \beta$-unsaturated aldehyde $\mathbf{6 g}$ underwent a redox reaction to give thioester $\mathbf{7 g}$ as a major product together with the Michael adduct in $11 \%$ yield, $\beta, \beta$-disubstituted unsaturated aldehyde $\mathbf{6 h}$ only gave the desired product $\mathbf{7 h}$ in $83 \%$ yield (entries 6 and 7). In a similar manner, several alkyl and aryl 20 thiols could be introduced to 3-phenylpropionaldehyde $\mathbf{6 a}$ in good yields (entries 8-12).

In summary, we found that phenazine was the best oxidant for the NHC-catalyzed direct thioesterification of aldehydes, and did not lead to the formation of any disulfides. Furthermore, the 25 appropriate combination of a NHC precatalyst and base (catalyst $\mathbf{A} / \mathrm{Et}_{3} \mathrm{~N}$, catalyst $\mathbf{B} / \mathrm{DBU}$ ) was shown to be important for the efficient thioesterification of aromatic and aliphatic aldehydes by redox activation.

This work was supported by a Grant-in-Aid for Scientific 30 Research on Innovative Areas "Advanced Molecular Transformations by Organocatalysts" from The Ministry of Education, Culture, Sports, Science and Technology, Japan.

\section{Notes and references}

${ }^{a}$ Graduate School of Pharmaceutical Sciences, Kyoto University, Sakyo35 ku, Kyoto, 606-8501, Japan. Fax: +81-75-753-4528; Tel: +81-75-7534569; E-mail: takemoto@pharm.kyoto-u.ac.jp

$\dagger$ This article is part of the joint ChemComm-Organic \& Biomolecular Chemistry 'Organocatalysis' web-theme issue.

$\ddagger$ Electronic Supplementary Information (ESI) available. For ESI see 40 DOI: $10.1039 / \mathrm{b} 000000 x$

1 (a) D. Crich and I. Sharma, Angew. Chem., Int. Ed., 2009, 48, 2355; (b) D. Crich and K. Sasaki, Org. Lett., 2009, 11, 3514; (c) M. Benaglia, M. Cinquini and F. Cozzi, Eur. J. Org. Chem., 2000, 563

45 (d) K. Narasaka, F. Kanai, M. Okudo and N. Miyoshi, Chem. Lett., 1989, 18, 1187; (e) R. L. Danheiser and J. S. Nowick, J. Org. Chem., 1991, 56, 1176; (f) K. Matsuo and M. Sindo, Org. Lett., 2010, 12, 5346; (g) S. Iimura, K. Manabe and S. Kobayashi, Org. Lett., 2003, $5,101$.

${ }_{50} 2$ (a) P. E. Dawson, T. W. Muir, I. Clark-Lewis and S. B. H. Kent, Science, 1994, 266, 776; (b) P. E. Dawson and S. B. H. Kent, Annu. Rev. Biochem., 2000, 69, 923.

3 (a) H. Tokuyama, S. Yokoshima, T. Yamashita, S.-C. Lin, L. Li and T. Fukuyama, J. Braz. Chem. Soc., 1998, 9, 381; (b) T. Fukuyama and H. Tokuyama, Aldrichimica Acta., 2004, 37, 87; (c) L. S. Liebeskind and J. Srogl, J. Am. Chem. Soc., 2000, 122, 11260; (d) H. Yang, H. Li, R. Wittenberg, M. Egi, W. Huang and L. S. Liebeskind, J. Am. Chem. Soc., 2007, 129, 1132; (e) R. Wittenberg, J. Srogl, M. Egi and L. S. Liebeskind, Org. Lett., 2003, 5, 3033; (f) H. Li, H.

60 Yang and L. S. Liebeskind, Org. Lett., 2008, 10, 4375; (g) K. Kunchithapatham, C. C. Eichman and J. P. Stambuli, Chem. Commun., 2011, DOI: 10.1039/C1CC16114H.
4 (a) J. M. Yost, G. Zhou and D. M. Coltart, Org. Lett., 2006, 8, 1503; (b) S. Rossi, M. Benaglia, F. Cozzi, A. Genoni and T. Benincori, Adv Synth. Catal., 2011, 353, 848; (c) N. Utsumi, S. Kitagaki and C. F. Barbas Ш, Org. Lett., 2008, 10, 3405; (d) D. A. Alonso, S. Kitagaki, N. Utsumi and C. F. Barbas Ш, Angew. Chem., Int. Ed., 2008, 47, 4588; (e) A. Iida, J. Osada, R. Nagase, T. Misaki and Y. Tanabe, Org. Lett., 2007, 9, 1859.

705 J. Staunton and K. J. Weissman, Nat. Prod. Rep., 2001, 18, 380.

6 (a) S. limura, K. Manabe and S. Kobayashi, Chem. Commun., 2002, 94; (b) A. R. Katritzky, A. A. Shestopalov and K. Suzuki, Synthesis, 2004, 11, 1806.

7 With acyl chloride: (a) H. M. Meshram, G. S. Reddy, K. H. Bindu 75 and J. S. Yadav, Synlett, 1998, 877; (b) S. Ahmad and J. Iqbal, Tetrahedron Lett., 1986, 27, 3791. With ester: (c) S. Magens and B. Plietker, Chem. Eur. J., 2011, 17, 8807.

8 H. Cao, L. McNamee and H. Alper, J. Org.Chem., 2008, 73, 3530.

9 (a) H. Nambu, K. Hata, M. Matsugi and Y. Kita, Chem. Commun., 2002, 1082; (b) H. Nambu, K. Hata, M. Matsugi and Y. Kita, Chem. Eur. J., 2005, 11, 719; (c) S. B. Bandgar, B. P. Bandgar, B. L. Korbad and S. S. Sawant, Tetrahedron Lett., 2007, 48, 1287.

10 Reviews of NHC-catalyzed reactions: (a) D. Enders, O. Niemeier, and A. Henseler, Chem. Rev., 2007, 107, 5606; (b) K. Zeitler, Angew. Chem., Int. Ed., 2005, 44, 7506; (c) H. U. Vora and T. Rovis, Aldricimica Atca., 2011, 44, 3. (d) J. Mahatthananchai and J. W. Bode, Chem. Sci., 2012, 3, 192-197.

11 Internal redox for ester synthesis: (a) N. T. Reynolds, J. Read de Alaniz and T. Rovis, J. Am. Chem. Soc., 2004, 126, 9518; (b) K. Y.90 K. Chow and J. W. Bode, J. Am. Chem. Soc., 2004, 126, 8126; (c) S. S. Sohn and J. W. Bode, Angew. Chem., Int. Ed., 2006, 45, 6021; (d) L. Wang, K. Thai and M. Gravel, Org. Lett., 2009, 11, 891; (e) K. B. Ling and A. D. Smith, Chem. Commun., 2011, 47, 373; (f) A. Chan and K. A. Scheidt, Org. Lett., 2005, 7, 905; (g) K. Zeitler, Org. Lett., 2006, 8, 637; (h) M. Yoshida, Y. Katagiri, W.-B. Zhu and K. Shishido, Org. Biomol. Chem., 2009, 7, 4062.

12 External redox for ester synthesis: (a) A. Miyashita, Y. Suzuki, I. Nagasaki, C. Ishiguro, K. Iwamoto and T. Higashino, Chem. Pharm. Bull., 1997, 45, 1254; (b) S. Shinkai, T. Yamashita, Y. Kusano and O. 100 Manabe, Tetrahedron Lett., 1980, 21, 2543; (c) S. De Sarker, S. Grimme and A. Studer, J. Am. Chem. Soc., 2010, 132, 1190; (d) B. E. Maki, A. Chan, E. M. Phillips and K. A. Scheidt, Org. Lett., 2007, 9, 371; (e) B. E. Maki and K. A. Scheidt, Org. Lett., 2008, 10, 4331; (f) H. Inoue and S. Tamura, J. Chem. Soc., Chem. Commun., 1986, 858; (g) J. Guin, S. De Sarkar, S. Grimme and A. Studer, Angew. Chem., Int. Ed., 2008, 47, 8727; (h) R. S. Reddy, J. N. Rosa, L. F. Veiros, S. Caddick and P. M. P. Gois. Org. Biomol. Chem., 2011, 9, 3126; (i) C. Noonan, L. Baragwanath and S. J. Connon, Tetrahedron Lett., 2008, 49, 4003.

11013 Internal redox for amide synthesis: (a) H. U. Vora and T. Rovis, $J$. Am. Chem. Soc., 2007, 129, 13796; (b) J. W. Bode and S. S. Sohn, J. Am. Chem. Soc., 2007, 129, 13798; (c) Y. Kawanaka, E. M. Phillips and K. A. Scheidt, J. Am. Chem. Soc., 2009, 131, 18028; (d)G.-Q. Li, Y. Li, L.-X. Dai and S.-L. You, Org. Lett., 2007, 9, 3519.

11514 External redox for amide synthesis: S. De Sarkar and A. Studer, Org .Lett., 2010, 12, 1992.

15 Y. Kageyama and S. Murata, J. Org. Chem., 2005, 70, 3140.

16 (a) B. Wanner, J. Mahatthananchai and J. W. Bode. Org. Lett., 2011, 13, 5378; (b) S. De Sarkar and A. Studer, Angew. Chem., Int. Ed., 120 2010, 49, 9266; (c) Z.-Q. Rong, M.-Q. Jia and S.-L. You, Org. Lett., 2011, 13, 4080.

17 S. Iwahana, H. Iida and E. Yashima, Chem. Eur. J., 2011, 17, 8009.

18 S.-L. Zhang, H.-X. Xie, J. Zhu, H. Li, X.-S. Zhang, J. Li and W. Wang, Nat. Commun., 2011, $2,211$. 